\title{
Can early palliative care with anticancer treatment improve overall survival and patient-related outcomes in advanced lung cancer patients? A review of the literature
}

\author{
Massimo Ambroggi ${ }^{1} \cdot$ Claudia Biasini $^{1} \cdot$ Ilaria Toscani ${ }^{1} \cdot$ Elena Orlandi ${ }^{1} \cdot$ Raffaella Berte $^{1} \cdot$ Martina Mazzari $^{2}$. \\ Luigi Cavanna ${ }^{1}$
}

Received: 30 October 2017 / Accepted: 26 March 2018 / Published online: 27 April 2018

(C) The Author(s) 2018, corrected publication June/2018

\begin{abstract}
Purpose Metastatic non-small-cell lung cancer (NSCLC), the leading cause of death from cancer worldwide, is a debilitating disease that results in a high burden of symptoms and poor quality of life; the estimated prognosis after the diagnosis has been established was less than 1 year until some years ago. At the present, the new targeted therapies and immunotherapy are changing the course of the disease. However, advanced NSCLC remains an incurable disease, with a poor prognosis for the majority of the affected patients, so that quality of life and relief from symptoms are primary objectives of treatment. Some evidences suggest that early palliative care (EPC) for these patients can improve quality of life and even survival.

Design A systematic review of the studies evaluating the impact on objective and on patient-reported outcomes of the introduction of EPC in opposition to standard care (SC), for advanced lung cancer patients, was performed. Because of the small number of studies conducted in this area, retrospective studies were also considered for the review.

Results Five studies were included because they matched the inclusion criteria previously defined as relevant for the study. The review found that both survival and quality of life were better for patients included in EPC groups.

Conclusions While results of the studies included in this review are not always comparable because different methods and scales have been used, there is enough evidence for clinical oncologists to implement the use of EPC in clinical practice for advanced lung cancer patients.
\end{abstract}

Keywords Early palliative care · Advanced lung cancer · Survival · Quality of life

\section{Introduction}

Patients with advanced cancer frequently develop devastating physical and psychosocial symptoms, requiring individualized assessment and management. In addition, patients frequently develop functional decline, along with spiritual and financial concerns [1]. Their primary caregivers and other family members may also experience physical and emotional distress, necessitating a combination of counseling and education about the patients'

Luigi Cavanna

1.cavanna@ausl.pc.it

1 Departments of Oncology-Hematology, Ospedale "G. da Saliceto", via taverna 49, 29121 Piacenza, Italy

2 Departments of Pharmacy, Ospedale "G. da Saliceto", via taverna 49, 29121 Piacenza, Italy illnesses. Furthermore, patients and their families require discussions regarding goals of care and advanced-care planning for their future health care needs [2].

Palliative care can be defined as " $\ldots$ an approach that improves the quality of life of patients and their families, facing the problem associated with life-threatening illness, through the prevention and relief of suffering by means of early identification and impeccable assessment and treatment of pain and other problems, physical, psychosocial, and spiritual" [3]. During the last few decades, palliative care has acquired expertise in symptom management, psychosocial care, communication, complex decision making, and transition of care. Since the opening of the first palliative care unit in Montreal, Canada, in 1976 [4], these programs have become available at a large number of acute care hospitals and cancer centers around the world [5]. Palliative medicine is now a recognized specialty in many countries, and it has a growing evidence base for improving quality of care $[6,7]$; however, cancer 
patients continue to be referred to these programs in low numbers and late in the trajectory of illness [8].

More recently, it must be emphasized that in addition to the more traditional inpatient consultation service of palliative care physicians $[9,10]$, palliative care teams increasingly provide outpatient services, so patients can be referred early in the trajectory of illness [11]. Even though there has been a significant increase in the use of palliative care by oncologists [12], the referral of patients to palliative care occurs too late in the trajectory of illness at an average of 30 to 60 days before death $[8,13]$. The majority of families referred to palliative care programs state that they would have preferred an earlier consultation $[14,15]$. Indeed, early referral to palliative care can facilitate timely diagnosis and treatment of symptoms, longitudinal psychosocial support, and counseling, as well as a gradual transition of care. There is emerging evidence that early incorporation of palliative care principles can improve patients' quality of life while minimizing caregiver distress and aggressive measures at the end of life [16, 17].

Given that almost all patients with cancer seen by the palliative care team are referred by oncologists rather than selfreferred, oncologists have a critical role in deciding on the need for and the timing of referral, and it must be emphasized that all cancer patients should have access to good symptom control and emotional support when the needs arise, and those with refractory physical and/or psychosocial distress should be referred promptly [18].

One of the key barriers to early referral is the misunderstanding that palliative care is only provided at the end of life once patients have exhausted all cancer treatment options [18]. Some oncologists have expressed the concern that a referral to palliative care would destroy a patient's hope [19]. It is important to recognize that patients do not need to choose between cancer treatments and supportive/palliative care. Rather, they can take advantage of the expertise of both the oncology and the palliative care teams in optimizing quantity and quality of life under a simultaneous care model [20-22]. This is particularly important in the actual era of targeted therapy and immunotherapy, which has seen an explosion of novel therapeutic options considered less toxic than traditional chemotherapy, making these treatments feasible in patients previously treated with poor performance status and even closer to the end of life [18].

Metastatic non-small-cell lung cancer (NSCLC), the leading cause of death from cancer worldwide [23], is a debilitating disease that results in a high burden of symptoms and poor quality of life; the estimated prognosis after the diagnosis has been established was less than 1 year [24-27] until a few years ago. At the present, the new targeted therapies are changing the course of this disease, especially for patients having tumors presenting some gene mutations drivers, like mutations activating EGFR [28, 29], ALK translocation [30, 31], ROS rearrangement [32], Met amplification or mutation [33] and, more recently, also the introduction of immunotherapy changes the prognosis of metastatic NSCLC [34-36]. However, advanced NSCLC remains an incurable disease, with a poor prognosis for the majority of patients, so that quality of life and relief from symptoms remain primary objectives of treatment.

In 2007, Temel et al. [37] in a phase II study demonstrated the feasibility and efficacy of early palliative care (EPC) combined with anticancer therapy in advanced NSCLC, and subsequently, in a phase III study, also a better overall survival (OS) between patients in the EPC group was demonstrated by the same authors [24]. After this study, other trials investigated the role of adding EPC to SC to improvement of OS and patient-related outcomes for advanced NSCLC patients. We collected all the studies conducted and published in this field and evaluated their results: its goal is essentially to evaluate if there is enough evidence to recommend the introduction of early palliative care in the real world for advanced NSCLC patients.

\section{Methods}

We provide a systematic review of the published data. The methodology PRISMA statement suggested in previous papers was applied for this review [38].

\section{Inclusion and exclusion criteria}

Studies that evaluated the impact of EPC on OS and QoL (measured with different scales), compared to standard care only (SC), for advanced lung cancer patients were included in this review. SC was represented by chemotherapy plus supportive therapy to prevent/treat adverse events chemotherapy related; however, chemotherapy differed by institutions or countries: in general, for advanced/metastatic NSCLC, platinum-based chemotherapy and paclitaxel is performed in the USA, and platinum-based chemotherapy and gemcitabine or pemetrexed is performed in Europe. The timing of introduction of EPC is different in the different studies, early means at diagnosis or as soon as possible after diagnosis. The primary endpoint of this review is OS, the secondary endpoint QoL. Because of the small number of studies conducted in this area, retrospective studies were also considered for the review, but only if they included a control arm, SC, so that a comparison could be made.

\section{Study identification}

A computerized literature search through PubMed, CANCER-LIT, Embase, and Cochrane Library was performed applying this strategy: (lung cancer[Title/Abstract] 
OR lung neopla* [Title/Abstract] OR lung tumor[Title/ Abstract] OR lung tumor[Title/Abstract] OR NSCLC[Title/ Abstract] OR non-small-cell lung cancer[Title/Abstract]) AND (early palliative care[Title/Abstract]). Reports and abstracts were also identified by back-referencing from the original and relevant studies. Only studies published in English before May 312017 were selected for the present review. Studies published only in abstract form were excluded. Four co-authors (M.A., M.M., I.T., and E.O.) evaluated the titles and abstracts and then the full text of the studies considered potentially eligible for the present review. If in doubt, a fifth author (L.C.) was consulted to reach an agreement.

\section{Data extraction and analysis}

Three co-authors (M.A., C.B., and L.C.) independently extracted qualitative and numerical data from the included studies, resolved differences through consensus, and analyzed the data qualitatively and quantitatively.

\section{Results}

The total number of articles identified in our search was 25 ; only five studies [24, 39-42] were included because they matched the inclusion criteria, defined before as relevant for the study (Fig. 1). The main characteristics of the included studies are summarized in Table 1. Four of these five studies
[24, 39-41], involving 644 patients, evaluated OS, and three of them $[24,39,42]$ evaluated QoL, measured with different scales, involving 443 patients. For studies including other cancer patients in addition with lung cancer, only patients with lung cancer were considered in this review. Studies' outcomes are summarized in Table 2. OS was better for EPC group in almost all studies that evaluated this endpoint [24, 40,41], and the difference was always statistically significant; in addition, better OS in EPC group was often associated with less chemotherapy near the end of life. QoL was also almost always better for EPC group, and the difference was greater with the increase in average observation. The studies analyzed have also some limitations/biases, summarized in Table 3.

The study by Temel et al. [24] was the first randomized controlled trial that evaluated the early introduction of palliative care in advanced NSCLC patients. The primary outcome of the study was the change in QoL at 12 weeks; eligible patients were enrolled within 8 weeks after diagnosis and were randomly assigned to one of the two groups in a 1:1 ratio without stratification. This study evaluated also OS, calculated from the time of enrollment to the time of death or to December 1, 2009 for patients still alive (but the study was not designed specifically for OS). Median estimates of survival were as follows: 9.8 months (95\% confidence interval [CI] 7.9 to 11.7 ) in the entire sample (151 patients), 11.6 months (95\% CI 6.4 to 16.9 ) in the EPC group (77 patients), and 8.9 months (95\% CI 6.3 to 11.4 ) in the SC group (74 patients) ( $p=0.02$ with the use of the log-rank test). After adjustment

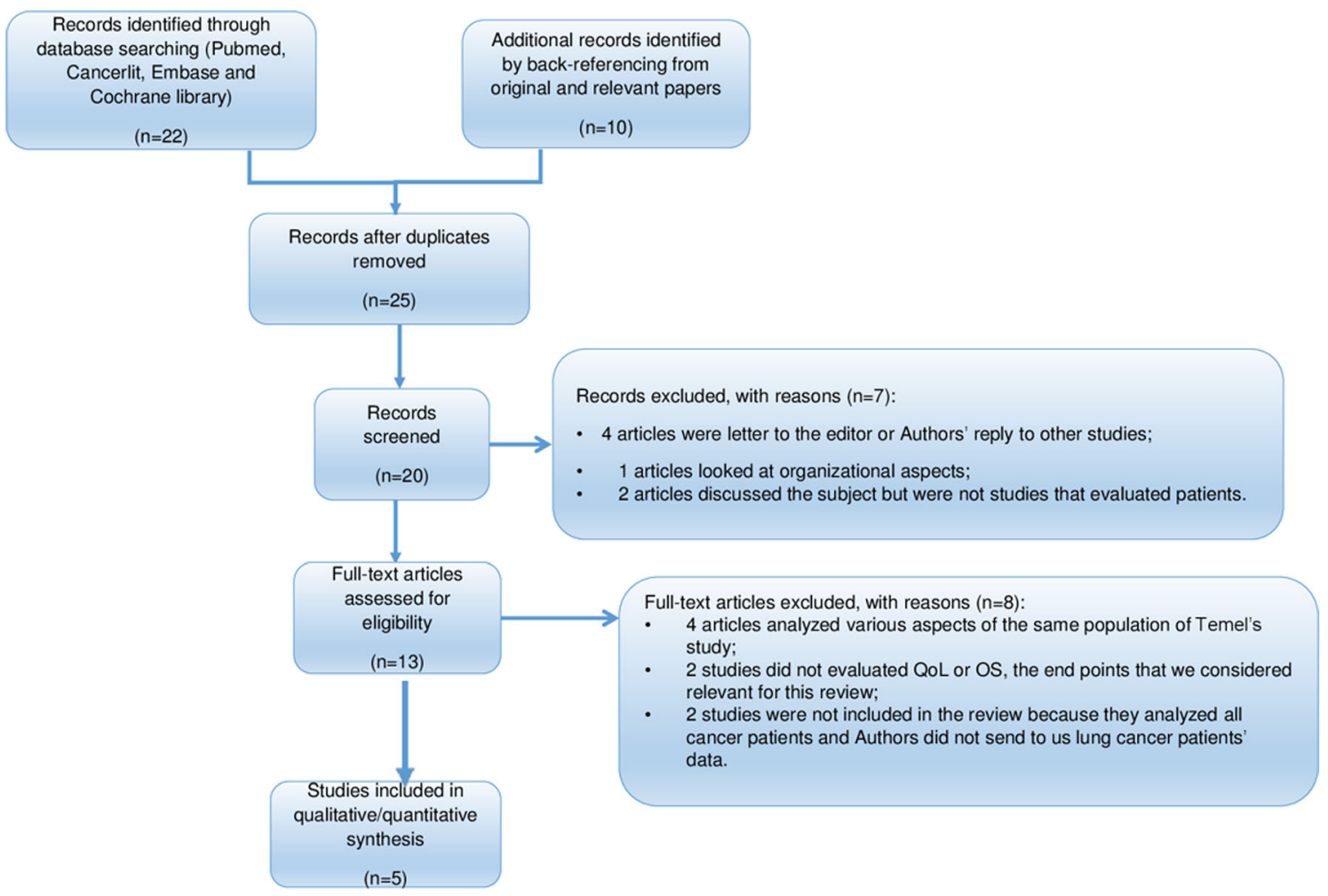

Fig. 1 The PRISMA statement flow diagram [38] 
for age, sex, and baseline Eastern Cooperative Oncology Group (ECOG) performance status, the group assignment remained a significant predictor of survival (hazard ratio for death in the standard care group $1.70,95 \%$ CI 1.14 to 2.54 , $p=0.01$ ) [24].

Another study evaluating OS was that conducted by Zimmermann et al. [39]. In this cluster-randomized trial of 461 patients with advanced cancer, 101 patients were affected by lung cancer: 55 were referred to EPC group and 46 to SC group. The primary outcome of the study regarded QoL. Considering only lung cancer patients' data, we can observe that there were more deaths in the intervention group (3/46 at 3 months and 5/46 at 4 months) rather than in the control group (7/55 at 3 months and 9/55 at 4 months).

Two other studies, both retrospective (which represents their main limit), evaluated OS [40,41] that was better for the EPC group in both studies, and the difference was statistically significant.

In the study by Nieder et al. [40], EPC group was compared with late palliative care and with no palliative care. OS was significantly better for the EPC group, in particular: median survival was 14.0 months in patients who received additional early palliative care, 6.7 months in the late palliative care, and 7.7 months in the no palliative care groups ( $p=0.001$, pooled over strata). In this study, patients who received additional palliative care were significantly more likely to be treated with systemic anticancer drugs and with more lines of therapy, particularly in the early additional palliative care group.

In the study by King et al. [41], conducted at a single tertiary comprehensive cancer center, a significant prolonged survival was observed in patients in the EPC compared to the SC group, after adjusting for age, performance status, and disease type: 11.9 vs 10.1 months, adjusted $\mathrm{HR}=0.72, p=0.032$, and EPC group was identified as an independent predictor for overall survival, like in the study by Temel et al. [24].

The other endpoint we considered relevant for this review, QoL, was analyzed in three of the five included studies [24, 39, 42], all prospective, and it was measured with different scales. QoL is a patient-reported outcome, it is not objective, and it depends on patients' answers to different questions. The QoL scales used varied by the studies, but they demonstrated almost always that EPC patients felt better than SC group, by measuring the difference in the score from the baseline to different times of follow-up, depending on the study. Interestingly, often the score was better (indicative of better quality of life) by increasing the observation period: for example, in the most recent study conducted by Temel et al. [42], Functional Assessment of Cancer Therapy-General (FACT-G) score was much better at 24 than at 12 weeks from baseline.

The first published study, by Temel et al. [24], evaluated QoL by measuring change in three scales' (Functional 


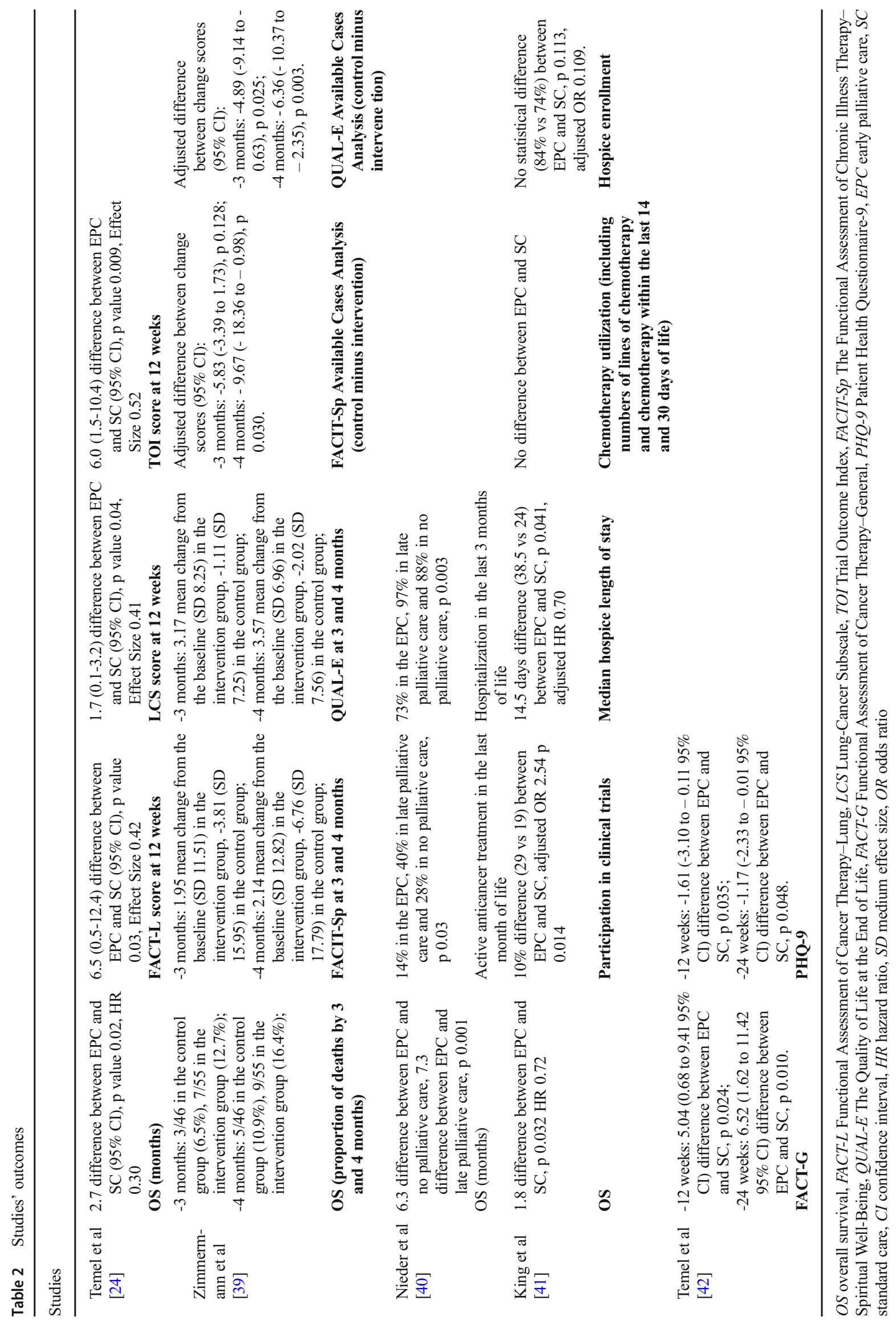


Table 3 Limitations/risks of bias of the studies

\begin{tabular}{|c|c|}
\hline Studies & Limitations/risks of bias \\
\hline Temel et al. [24] & $\begin{array}{l}\text { (1) The study was performed at a single, tertiary care site with a specialized group } \\
\text { of thoracic oncology providers and palliative care clinicians, thereby limiting } \\
\text { generalization of the results to other care settings. (2) The sample lacked diversity with } \\
\text { respect to race and ethnic group. (3) Clinicians did not deny palliative care consultations } \\
\text { to participants receiving standard care, and a small minority of patients in the standard } \\
\text { care group was seen by the palliative care team. }\end{array}$ \\
\hline $\begin{array}{l}\text { Zimmermann } \\
\text { et al. [39] }\end{array}$ & $\begin{array}{l}\text { (1) The trial was done at one center. (2) Authors cannot exclude that the benefits of the } \\
\text { intervention were attributable to increased attention in general, rather than specifically } \\
\text { from a palliative care team, but attention to concerns of patients is itself an important } \\
\text { aspect of palliative care. (3) There was also selection bias, which is common in } \\
\text { cluster-randomized studies because of randomization of clusters before consent of } \\
\text { individuals; a larger number of patients declined participation in the intervention group, } \\
\text { including because of lack of symptoms. Aware of this potential limitation, authors } \\
\text { opted for cluster randomization to maximize recruitment, and were able to attain their } \\
\text { planned sample size. Probably in the intervention group, there were more ill patients, } \\
\text { and this aspect could explain because there were more deaths in this group. }\end{array}$ \\
\hline Nieder et al. [40] & $\begin{array}{l}\text { (1) Retrospective trial. (2) Lack of standardized treatment protocol; the additional } \\
\text { intervention was at the discretion of the treating physicians and timing was not } \\
\text { standardized. (3) Only } 22 \text { out of } 286 \text { patients received early palliative care. } \\
\text { (4) Data derived from a single institution. }\end{array}$ \\
\hline King et al. [41] & $\begin{array}{l}\text { (1) Retrospective, not randomized trial (“quasi-randomization"). (2) The study represents } \\
\text { the experience of a single, tertiary comprehensive cancer center with specialized } \\
\text { thoracic oncology providers and a single specialized provider dually training in } \\
\text { oncology and palliative care. (3) Standardized scales for symptom or psychological } \\
\text { assessments were not routinely used by either group over time. }\end{array}$ \\
\hline Temel et al. [42] & $\begin{array}{l}\text { (1) The study included lung and GI cancer patients. Authors did not anticipate the } \\
\text { difference in QOL and mood trajectories between patients with lung and GI cancers; } \\
\text { thus, they did not plan the sample size to evaluate outcomes by cancer subtype. (2) } \\
\text { Because usual care at authors' institution often entails involvement of PC in the } \\
\text { outpatient setting, more than one third of patients who were assigned to usual care met } \\
\text { with the PC team during the first } 24 \text { weeks of the study, and this contact may have } \\
\text { diluted the effect of the intervention, though such practice likely represents current } \\
\text { national standards. (3) The trial was conducted at a single institution, with a } \\
\text { predominantly white and English-speaking population, which may limit the } \\
\text { generalizability of the results to other care settings and clinical populations. }\end{array}$ \\
\hline
\end{tabular}

Assessment of Cancer Therapy-Lung (FACT-L), lung-cancer subscale LCS of the FACT-L, and Trial Outcome Index TOI) score at 12 weeks. A comparison of measures of QoL at 12 weeks showed that EPC group patients had significantly higher scores than did SC group patients, for the total FACT-L scale, the LCS, and the TOI, with effect sizes in the medium range. In addition, the percentage of patients with depression at 12 weeks, as measured by the Hospital Anxiety and Depression Scale (HADS) and lower depression symptom (PHQ-9), was significantly lower in the EPC group than in the SC group, although the proportions of patients receiving new prescriptions for antidepressant drugs were similar in the two groups (approximately 18\% in both groups, $p=1.00$ ). The percentage of patients with elevated scores for symptoms of anxiety did not differ significantly between the groups.

Temel et al. conducted another recent study [42], where patients affected by gastrointestinal (GI) and lung cancer were included; the primary endpoint was change in QoL from baseline to week 12, per scoring by the FACT-G scale. Secondary endpoints included change in QoL from baseline to week 24, change in depression per the Patient Health Questionnaire-9 (PHQ-9), and differences in end-of-life communication. In this study, only lung cancer patients were considered for this review. Intervention patients reported a mean 0.39-point increase in FACT-G scores from baseline to 12 weeks compared with usual care patients who reported a 1.13-point decrease from baseline $(t[296]=20.96, \mathrm{SE}=1.59, p=0.339$, Cohen's $d 0.11$ ). At 24 weeks, intervention patients reported a 1.59point increase in FACT-G scores from baseline, whereas usual care patients reported a 3.40-point decrease from baseline $(t$ $[238]=22.59, \mathrm{SE}=1.9, p=0.010$, Cohen's $d 0.33$ ). PHQ-9, HADS-Depression, and HADS-Anxiety scores did not differ significantly between study groups from baseline to weeks 12 or 24; however, ANCOVA models that controlled for baseline variables demonstrated significant differences that favored the intervention for FACT-G and PHQ-9 scores at 24 weeks. Using the terminal decline model, intervention participants had significantly higher QoL (FACT-G) and lower depression symptom (PHQ-9) scores at 2 and 4 months, but not at 6 months, before death. Use of psychosocial services, 
including psychiatry, psychology, and social work, did not differ between study groups [42].

In the study by Zimmermann et al. [39], changing in QoL scales was the primary outcome. Functional Assessment of Chronic Illness Therapy-Spiritual Well-Being (FACIT-SP) and Quality of Life at the End of Life (QUAL-E) were evaluated for lung cancer patients, and the changes at 3 and 4 months favored the intervention group, despite the fact that patients in this group were more ill due to a selection bias.

In the study by Nieder et al. [40], active anticancer treatment in the last month of life and hospitalization in the last 3 months of life were analyzed in addition to OS. Patients who received early or late additional palliative care were significantly younger than those who did not receive additional palliative care $(p=0.005)$. Patients who received additional palliative care were significantly more likely to be treated with systemic anticancer drugs and with more lines of therapy, particularly in the EPC group $(p=0.001)$.

In the study by King et al. [41], chemotherapy utilization, participation in clinical trials, and hospice resource utilization were evaluated in addition to OS. Chemotherapy utilization, including numbers of lines of chemotherapy and chemotherapy within the last 14 and 30 days of life, did not differ between the groups.

\section{Discussion}

From the studies included in the review, both OS and patient-reported outcomes are better in EPC than SC group, suggesting that early introduction of palliative care for lung cancer patients could be recommended. OS is almost always longer for EPC patients, 2 months longer, more or less, in two studies [24, 41] and about 7 months longer in another study [40]. Maybe OS or progressionfree survival (PFS) are better by introducing new drugs, but often they are shorter. EPC, a new approach in patients' care, without using new drugs or advanced surgical o radiotherapy techniques, can obtain better quality of life and OS. Interestingly, it was demonstrated that EPC patients more often receive chemotherapy, and more lines of chemotherapy, but receive less aggressive end-of-life care $[24,40]$, such as chemotherapy in the last month of life. In the study by Temel et al. [24], 33\% of patients in EPC group received aggressive end-of-life care compared to $54 \%$ of patients in SC group ( $p=0.05)$; in addition, fewer patients in the SC group than in the EPC group had resuscitation preferences documented in the outpatient electronic medical record, an essential step in clarifying and ensuring respect for patients' wishes about their care at the end of life [24]. It must be emphasized that less aggressive end-of-life care did not adversely affect survival, while EPC patients, as compared with SC patients, had improved survival. Furthermore, the improvement observed in the quality of life among EPC patients, as indicated by a mean change in the TOI score by 12 weeks that was approximately 5 points higher than in the SC group, is similar to the improvement in the quality of life that has been observed among patients who have a response to cisplatin-based chemotherapy [24]. Despite similar cancer therapies in the two study groups, EPC patients had an improved quality of life, as compared with SC. Rates of depression also differed significantly between the groups, with approximately half as many patients in the EPC group as in the SC group reporting clinically significant depressive symptoms on the HADS, and this effect was not due to a between group difference in the use of antidepressant agents [24]. Previous data have shown that a lower quality of life and depressed mood are associated with shorter survival among patients with metastatic nonsmall-cell lung cancer. So, authors hypothesized that improvements in both of these outcomes among EPC patients may account for the observed survival benefit. In addition, the integration of palliative care with standard oncologic care may facilitate the optimal and appropriate administration of anticancer therapy, especially during the final months of life. With earlier referral to a hospice program, patients may receive care that results in better management of symptoms, leading to stabilization of their condition and prolonged survival. However, as previously reported, these hypotheses require further study [24].

We think that there are two main aspects to consider in the study of Temel et al. [24]: the generalizability of authors' findings (because all patients with a new diagnosis of metastatic non-small-cell lung cancer were eligible), the low rate of loss to follow-up, and the high percentage of participants who completed the study assessments. The limitations of this study are related to the fact that it was performed at a single, tertiary care site with a specialized group of thoracic oncology providers and palliative care clinicians, and palliative care consultations were not denied to participants in the SC group.

In the study by Nieder et al. [40], the likelihood of active anticancer treatment in the last month of life was lowest in the early additional palliative care group: 14 as compared to $40 \%$ in the late palliative care and $28 \%$ in the no palliative care group, $p=0.03$. Patients who received early or late additional palliative care were significantly less likely to lack a documented resuscitation preference (typically a do not resuscitate order); rates were $0 \%$ in the early palliative care group, $13 \%$ in the late palliative care group, and $24 \%$ in the no palliative care group. In the early palliative care group, the majority of patients $(61 \%)$ had their resuscitation preference documented earlier than in the last month of life, by contrast with $12 \%$ of patients in the late palliative care group, and $18 \%$ in the no palliative care group; in addition, patients who received early additional palliative care were significantly less likely to become hospitalized in the last 
3 months of life: 73 vs $97 \%$ in the late and $88 \%$ in the no palliative care group.

In another retrospective study [41], EPC patients were more likely to participate in interventional clinical trials (29 vs $19 \%$, adjusted $\mathrm{OR}=2.54, p=0.014$ ), and it is well known that participation in randomized controlled trials is associated with improved cancer survival $[43,44]$. Although there was no difference in the frequency of hospice referrals between the two arms, the EPC group's hospice length of stay was 14 days longer than SC (38.5 vs 24 , adjusted $\mathrm{HR}=0.70, p=0.041$ ), and previously published data suggest that hospice enrollment may have an impact on survival. These data support the finding that hospice participation does not intrinsically shorten life as EPC patients were enrolled on hospice for 2 weeks longer with longer survival [41].

The European Society for Medical Oncology (ESMO) has been leading the way since 2003 by formally accrediting Designated Centers of Integrated Oncology and Palliative Care (ESMO-DCs). In 2006, the Italian Association of Medical Oncology (AIOM), according to the ESMO program, set up the Simultaneous and Continuous Care (SCC) Task Force with the main goals of training oncologists in palliative medicine and spreading the culture of integration between oncologists and palliative care teams in every oncology unit in Italy [45].

Recently, an article has been published by the AIOM Simultaneous and Continuous Care Task Force that represents the position of Italian medical oncologists about simultaneous care (that is the result of early integration of palliative care with cancer-directed treatments), and it is the result of a twostep project: a Web-based survey among medical oncologists and a consensus conference. Such a simultaneous approach requires a cultural change in oncologists, and several organizational barriers can hinder the efforts of individual operators. As highlighted in the document-derived recommendations, early activation of palliative care concomitant to cancerdirected treatment in the setting of advanced/metastatic disease is considered one of the top priorities by the community of Italian medical oncologists [45].

In conclusion, we observed from the analyzed studies that EPC for advanced lung cancer patients improve both objective (OS) and patient-reported (QoL) outcomes. Although the results of these studies are not always well comparable because different methods and scales have been used, in our opinion there is enough evidence for oncologists to implement the use of EPC in clinical practice for advanced lung cancer patients.

\section{Compliance with ethical standards}

Conflicts of interest The authors declare that they have no conflicts of interest.

Open Access This article is distributed under the terms of the Creative Commons Attribution-NonCommercial 4.0 International License (http:// creativecommons.org/licenses/by-nc/4.0/), which permits any noncommercial use, distribution, and reproduction in any medium, provided you give appropriate credit to the original author(s) and the source, provide a link to the Creative Commons license, and indicate if changes were made.

\section{References}

1. Dalal S, Del Fabbro E, Bruera E (2006) Symptom control in palliative care: part I - oncology as a paradigmatic example. J Palliat Med 9:391-408

2. Zaider T, Kissane D (2009) The assessment and management of family distress during palliative care. Curr Opin Support Palliat Care 3:67-71

3. World Health Organization: National Cancer Control Programmes: policies and managerial guidelines. http:/www.who.int/cancer/ palliative/definition/en/

4. Mount BM (1976) The problem of caring for the dying in a general hospital; the palliative care unit as a possible solution. Can Med Assoc J 115:119-121

5. Bruera E, Sweeney C (2002) Palliative care models: international perspective. J Palliat Med 5:319-327

6. Higginson IJ, Finlay I, Goodwin DM, Cook AM, Hood K, Edwards AGK, Douglas HR, Norman CE (2002) Do hospital-based palliative teams improve care for patients or families at the end of life? J Pain Symptom Manag 23:96-106

7. Higginson IJ, Finlay IG, Goodwin DM, Hood K, Edwards AGK, Cook A, Douglas HR, Normand CE (2003) Is there evidence that palliative care teams alter end-of-life experiences of patients and their caregivers? J Pain Symptom Mange 25:150-168

8. Hui D, Elsayem A, De la Cruz M et al (2010) Availability and integration of palliative care at US cancer centers. JAMA 303:1054-1061

9. Hui D, Elsayem A, Palla S, de la Cruz M, Li Z, Yennurajalingam S, Bruera E (2010) Discharge outcomes and survival of patients with advanced cancer admitted to an acute palliative care unit at a comprehensive cancer center. J Palliat Med 13:49-57

10. Braiteh F, El Osta B, Palmer JL et al (2007) Characteristics, findings, and outcomes of palliative care inpatient consultations at a comprehensive cancer center. J Palliat Med 10:948-955

11. Strasser F, Sweeney C, Willey J, Benisch-Tolley S, Palmer JL, Bruera E (2004) Impact of a half-day multidisciplinary symptom control and palliative care outpatient clinic in a comprehensive cancer center on recommendations, symptom intensity, and patient satisfaction: a retrospective descriptive study. J Pain Symptom Manag 27:481-491

12. Osta Be PJL, Paraskevopoulos T et al (2008) Interval between first palliative consult and death in patients diagnosed with advanced cancer at a comprehensive cancer center. J Palliat Med 11:51-57

13. Cheng WW, Willey J, Palmer JL, Zhang T, Bruera E (2005) Interval between palliative care referral and death among patients treated at a comprehensive cancer center. J Palliat Med 8:1025-1032

14. Morita T, Akechi T, Ikenaga M, Kizawa Y, Kohara H, Mukaiyama T, Nakaho T, Nakashima N, Shima Y, Matsubara T, Uchitomi Y (2005) Late referrals to specialized palliative care service in Japan. J Clin Oncol 23:2637-2644

15. Morita T, Miyashita M, Tsuneto S, Sato K, Shima Y (2009) Late referrals to palliative care units in Japan: nationwide follow-up survey and effects of palliative care team involvement after the cancer control act. J Pain Symptom Manag 38:191-196

16. Bakitas M, Lyons KD, Hegel MT, Balan S, Barnett KN, Brokaw FC, Byock IR, Hull JG, Li Z, Mckinstry E, Seville JL, Ahles TA (2009) The project ENABLE II randomized controlled trial to improve palliative care for rural patients with advanced cancer: baseline findings, methodological challenges, and solutions. Palliat Support Care 7:75-86

17. Wright AA, Zhang B, Ray A, Mack JW, Trice E, Balboni T, Mitchell SL, Jackson VA, Block SD, Maciejewski PK, Prigerson 
HG (2008) Associations between end-of-life discussions, patient mental health, medical care near death, and caregiver bereavement adjustment. JAMA 300:1665-1673

18. Bruera E, Hui D (2010) Integrating supportive and palliative care in the trajectory of cancer: establishing goals and models of care. J Clin Oncol 28(25):4013-4017

19. Freireich EJ, Kurzrock R (2009) The role of investigational therapy in management of patients with advanced metastatic malignancy. J Clin Oncol 27:304-306

20. Hui D, Elsayem A, Li Z, de la Cruz M, Palmer JL, Bruera E (2010) Antineopalstic therapy use in patients with advanced cancer admitted to an acute palliative care unit at a comprehensive cancer center: a simultaneous care model. Cancer 116:2036-2043

21. Hui D, Parsons HA, Nguywen L et al (2010) Timing of palliative care referral and symptom burden in phase I cancer patients: a retrospective cohort study. Cancer 116:4402-4409

22. Fadul N, Elsayem A, Palmer JL, del Fabbro E, Swint K, Li Z, Poulter V, Bruera E (2009) Supportive versus palliative care: what's in a name? - a survey of medical oncologists and midlevel providers at a comprehensive cancer center. Cancer 115:2013-2021

23. Jemal A, Siegel R, Ward E, Hao Y, Xu J, Thun MJ (2009) Cancer statistics. CA Cancer J Clin 59:225-249

24. Temel JS, Greer JA, Muzikansky A, Gallagher ER, Admane S, Jackson VA, Dahlin CM, Blinderman CD, Jacobsen J, Pirl WF, Billings JA, Lynch TJ (2010) Early palliative care for patients with metastatic non-small-cell lung cancer. N Engl J Med 363:733-742

25. Hopwood P, Stephens RJ (2000) Depression in patients with lung cancer: prevalence and risk factors derived from quality-of-life data. J Clin Oncol 18:893-903

26. Hopwood P, Stephens RJ (1995) Symptoms at presentation for treatment in patients with lung cancer: implications for the evaluation of palliative treatment. Br J Cancer 71:633-636

27. Lutz S, Norrel R, Bertucio C et al (2001) Symptom frequency and severity in patients with metastatic or locally recurrent lung cancer: a prospective study using the lung cancer symptom scale in a community hospital. J Palliat Med 4:157-165

28. Mok TS (2009) Gefitinib or carboplatin-paclitaxel in pulmonary adenocarcinoma. N Engl J Med 36:947-957

29. Rosell R, Carcereny E, Gervais R, Vergnenegre A, Massuti B, Felip E, Palmero R, Garcia-Gomez R, Pallares C, Sanchez JM, Porta R, Cobo M, Garrido P, Longo F, Moran T, Insa A, de Marinis F, Corre R, Bover I, Illiano A, Dansin E, de Castro J, Milella M, Reguart N, Altavilla G, Jimenez U, Provencio M, Moreno MA, Terrasa J, Muñoz-Langa J, Valdivia J, Isla D, Domine M, Molinier O, Mazieres J, Baize N, Garcia-Campelo R, Robinet G, RodriguezAbreu D, Lopez-Vivanco G, Gebbia V, Ferrera-Delgado L, Bombaron P, Bernabe R, Bearz A, Artal A, Cortesi E, Rolfo C, Sanchez-Ronco M, Drozdowskyj A, Queralt C, de Aguirre I, Ramirez JL, Sanchez JJ, Molina MA, Taron M, Paz-Ares L, Spanish Lung Cancer Group in collaboration with Groupe Français de Pneumo-Cancérologie and Associazione Italiana Oncologia Toracica (2012) Erlotinib versus standard chemotherapy as first-line treatment for European patients with advanced EGFR mutationpositive non-small-cell lung cancer (EURTAC): a multicenter, open-label, randomized phase 3 trial. Lancet Oncol 13:239-246

30. Shaw AT, Kim DW, Nakagawa K, Seto T, Crinó L, Ahn MJ, de Pas T, Besse B, Solomon BJ, Blackhall F, Wu YL, Thomas M, O'Byrne KJ, Moro-Sibilot D, Camidge DR, Mok T, Hirsh V, Riely GJ, Iyer S, Tassell V, Polli A, Wilner KD, Jänne PA (2013) Crizotinib versus chemotherapy in advanced ALK-positive lung cancer. N Engl J Med 368:2385-2394

31. Solomon BJ, Mok T, Kim DW, Wu YL, Nakagawa K, Mekhail T, Felip E, Cappuzzo F, Paolini J, Usari T, Iyer S, Reisman A, Wilner KD, Tursi J, Blackhall F, PROFILE 1014 Investigators (2014)
PROFILE 1014 investigators. First-line crizotinib versus chemotherapy in ALK-positive lung cancer. N Engl J Med 371:2167-2177

32. Mazieres J, Zalcman G, Crinò L et al (2015) Crizotinib therapy for advanced lung adenocarcinoma and a ROS1 rearrangement: results from the EUROS1 cohort. J Clin Oncol 33:992-999

33. Sadiq AA, Salgia R (2013) MET as a possible target for non-smallcell lung cancer. J Clin Oncol 31:1089-1096

34. Brahmer J, Reckamp KL, Baas P, Crinò L, Eberhardt WEE, Poddubskaya E, Antonia S, Pluzanski A, Vokes EE, Holgado E, Waterhouse D, Ready N, Gainor J, Arén Frontera O, Havel L, Steins M, Garassino MC, Aerts JG, Domine M, Paz-Ares L, Reck M, Baudelet C, Harbison CT, Lestini B, Spigel DR (2015) Nivolumab versus docetaxel in advanced squamous-cell nonsmall-cell lung cancer. N Engl J Med 373:123-135

35. Borghaei H, Paz-Ares L, Horn L, Spigel DR, Steins M, Ready NE, Chow LQ, Vokes EE, Felip E, Holgado E, Barlesi F, Kohlhäufl M, Arrieta O, Burgio MA, Fayette J, Lena H, Poddubskaya E, Gerber DE, Gettinger SN, Rudin CM, Rizvi N, Crinò L, Blumenschein GR Jr, Antonia SJ, Dorange C, Harbison CT, Graf Finckenstein F, Brahmer JR (2015) Nivolumab versus docetaxel in advanced nonsquamous nonsmall-cell lung Cancer. N Engl J Med 373:1627-1639

36. Herbst RS, Baas P, Kim DW, Felip E, Pérez-Gracia JL, Han JY, Molina J, Kim JH, Arvis CD, Ahn MJ, Majem M, Fidler MJ, de Castro G Jr, Garrido M, Lubiniecki GM, Shentu Y, Im E, Dolled-Filhart M, Garon EB (2016) Pembrolizumab versus docetaxel for previously treated, PDL1-positive, advanced non-small-cell lung cancer (KEYNOTE-010): a randomized controlled trial. Lancet 387:1540-1550

37. Temel JS, Jackson VA, Billings JA, Dahlin C, Block SD, Buss MK, Ostler P, Fidias P, Muzikansky A, Greer JA, Pirl WF, Lynch TJ (2007) Phase II study: integrated palliative care in newly diagnosed advanced non-small-cell lung cancer patients. J Clin Oncol 25(17):2377-2382

38. Liberati A, Altman DG, Tetzlaff J, Mulrow C, Gøtzsche PC, Ioannidis JPA, Clarke M, Devereaux PJ, Kleijnen J, Moher D (2009) The PRISMA statement for reporting systematic reviews and meta-analyses of studies that evaluate health care interventions: explanation and elaboration. J Clin Epidemiol 62(10):e1-e34

39. Zimmermann C, Swami N, Kryzanowska M et al (2014) Early palliative care for patients with advanced cancer: a clusterrandomised controlled trial. Lancet 383:1721-1730

40. Nieder C, Tollali T, Haukland E et al (2016) Impact of early palliative interventions on the outcomes of care for patients with nonsmall cell lung cancer. Support Care Cancer 24:4385-4391

41. King JD, Eikhoff J, Traynor A et al (2016) Integrated oncopalliative care associated with prolonged survival compared to standard care for patients with advanced lung cancer: a retrospective review. J Pain Symptom Manag 51(6):1027-1032

42. Temel JS, Greer JA, El-Jawahri A et al (2017) Effects of early palliative care in patients with lung and GI cancer: a randomized clinical trial. J Clin Oncol 35(8):834-841

43. Sabesan S, Piliouras P (2009) Disparity in cancer survival between urban and rural patients - how can clinicians help reduce it? Rural Remote Health 9:1146-1150

44. Ambroggi M, Biasini C, Del Giovane C et al (2015) Distance as a barrier to cancer diagnosis and treatment: review of the literature. Oncologist 20(12):1378-1385

45. Zagonel V, Franciosi V, Brunello A, Biasco G, Broglia C, Cattaneo D, Cavanna L, Corsi D, Farina G, Fioretto L, Gamucci T, Lanzetta G, Magarotto R, Maltoni M, Marchetti P, Massa E, Mastromauro C, Melotti B, Meriggi F, Nacci A, Pavese I, Piva E, Quirino M, Roselli M, Sacco C, Tonini G, Trentin L, Ucci G, Labianca R, Gori S, Pinto C, Cascinu S, AIOM Simultaneous \& Continuous Care (SCC), Task Force: ESMO Italian DCs (2017) Position paper of the Italian Association of Medical Oncology on early palliative care in oncology practice (simultaneous care). Tumori 103(1):9-14 